\title{
Outcomes and predictors of treatment response with sofosbuvir plus daclatasvir with or without ribavirin in Egyptian patients with genotype 4 hepatitis $C$ virus infection
}

This article was published in the following Dove Press journal:

Infection and Drug Resistance

\author{
Ossama A Ahmed' \\ Mohamed A Elsebaey ${ }^{2}$ \\ Mohamed Hassan A Fouad' \\ Heba Elashry ${ }^{3}$ \\ Ahmed I Elshafie' \\ Ahmed A Elhadidy ${ }^{2}$ \\ Noha E Esheba ${ }^{2}$ \\ Mohammed H Elnaggar ${ }^{2}$ \\ Shaimaa Soliman ${ }^{4}$ \\ Sherief Abd-Elsalam ${ }^{3}$ \\ 'Department of Internal Medicine, \\ Ain Shams University, Faculty of \\ Medicine, Cairo, Egypt; ${ }^{2}$ Department \\ of Internal Medicine, Tanta University, \\ Tanta, Egypt; ${ }^{3}$ Department of Tropical \\ Medicine and Infectious Diseases, \\ Faculty of Medicine, Tanta University, \\ Tanta, Egypt; ${ }^{4}$ Department of Public \\ Health and Community Medicine, \\ Menoufia University, Shbeen El-koum, \\ Egypt
}

Correspondence: Sherief Abd-Elsalam Department of Tropical Medicine, Tanta University Hospital, El Geish Street,

Tanta, Gharbia Governorate, Egypt

Tel +20 I095159522

Email sherif_tropical@yahoo.com

\begin{abstract}
Background and aims: Treatment of hepatitis $\mathrm{C}$ virus (HCV) changed dramatically with the introduction of oral direct-acting antiviral drugs due to their high antiviral potency and safety profile. Sofosbuvir plus daclatasvir combination therapy was extensively investigated in HCV genotypes 1,2, and 3, while published data regarding its real-life application in the treatment of genotype 4 is lacking. Therefore, we conducted this study to assess the outcomes and predictors of treatment response with sofosbuvir plus daclatasvir with or without ribavirin in Egyptian patients with genotype 4 hepatitis $\mathrm{C}$ virus infection.
\end{abstract}

Patients and methods: This prospective study included 300 Egyptian patients with chronic genotype $4 \mathrm{HCV}$, treated with sofosbuvir plus daclatasvir with or without ribavirin for 12-24 weeks. Primary outcome was the number of patients who achieved sustained virologic response (SVR12), and secondary outcome was the occurrence of adverse events.

Results: A total of $92.67 \%$ of all patients achieved SVR 12 . SVR 12 rates of $96.55 \%$ and $84.54 \%$ were reported in non-cirrhotic and cirrhotic patients, respectively. SVR12 in treatment-naïve and treatment-experienced patients were $94.12 \%$ and $87.01 \%$, respectively. A total of $19.7 \%$ of patients experienced mild adverse events. Older age, cirrhosis, and low platelet count were the predictors of treatment non-response.

Conclusion: Based on this multi-center prospective study, sofosbuvir plus daclatasvir with or without ribavirin for 12-24 weeks appears to have favorable outcomes in the treatment of genotype $4 \mathrm{HCV}$-infected Egyptian patients. Older age, cirrhosis, especially Child-Pugh class $\mathrm{B}$, and low platelet count are independent risk factors of treatment non-response.

Keywords: hepatitis C virus, genotype 4, sofosbuvir plus daclatasvir, sustained virologic response

\section{Introduction}

Hepatitis $\mathrm{C}$ virus (HCV) infection is a global public health problem affecting $\sim 184,000,000$ people worldwide. ${ }^{1}$ In Egypt, the prevalence of HCV infection among general population was estimated to be $15 \%$; $>90 \%$ of the infection was reported to be genotype $4 .^{2-6}$ Since HCV infection is one of the leading causes of liver cirrhosis, hepatocellular carcinoma (HCC), and liver transplantation globally, those patients with $\mathrm{HCV}$ are in need for effective antiviral therapy to halt the progression to these complications and hence reduce mortality. ${ }^{7-9}$

Treatment of HCV changed dramatically with the introduction of oral directacting antiviral (DAA) drugs due to their high antiviral potency and safety profile. ${ }^{10}$ 
DAA drugs are classified - according to their mechanism of action - into 3 main classes: NS3/4A protease inhibitors (e.g., boceprevir, telaprevir, simeprevir, asunaprevir, and paritaprevir boosted by ritonavir), NS5A replication complex inhibitors (e.g., daclatasvir, ledipasvir, and ombitasvir), and NS5B polymerase inhibitors (sofosbuvir and dasabuvir). ${ }^{11,12}$

Several oral DAA combination regimens for the treatment of genotype $4 \mathrm{HCV}$ (e.g., sofosbuvir plus ledipasvir, sofosbuvir plus simeprevir, or paritaprevir/ritonavir plus ombitasvir with our without ribavirin) were evaluated in many studies, which reported high SVR rates with few side effects. ${ }^{13-16}$ Sofosbuvir plus daclatasvir combination therapy was extensively investigated in HCV genotypes 1, 2, and 3, while published data regarding its real-life application in the treatment of genotype 4, particularly in Egypt, is lacking. ${ }^{17,18}$ Therefore, we conducted this study to assess the outcomes and predictors of treatment response with sofosbuvir plus daclatasvir with or without ribavirin in Egyptian patients with genotype $4 \mathrm{HCV}$ infection.

\section{Patients and methods}

This prospective study was conducted in outpatient clinics of internal medicine and tropical medicine departments in Ain Shams and Tanta University hospitals, Egypt. A total of 300 patients with chronic HCV infection were recruited from the outpatient clinics during the period from January 2016 to April 2017.

Approval of the Institutional Ethics Committee of Faculty of Medicine, Tanta University, Egypt, was obtained prior to the start of the study. A written informed consent was signed by each patient prior to enrollment; the study was registered at Clinicaltrials.gov (ClinicalTrials.gov ID: NCT02992457). All authors had access to the study data and reviewed and approved the final manuscript.

Patients with the following criteria were included in this study: age $>18$ years, positive $\mathrm{HCV}$ antibodies confirmed with a positive polymerase chain reaction (PCR) for HCV-RNA, treatment-naive or treatment-experienced, and Child-Pugh score $\leq 8$. Pregnant females, patients with renal impairment (serum creatinine $>2.5 \mathrm{mg} / \mathrm{dL}$ and estimated glomerular filtration rate $<30 \mathrm{~mL} / \mathrm{min} / 1.73 \mathrm{~m}^{2}$ ), patients with HCC (unless there was no evidence of activity by dynamic imaging 12 weeks after successful curative treatment) and patients with hepatitis B virus or human immunodeficiency virus coinfection were excluded from the study.

All patients were subjected to the following: thorough history taking, clinical examination, complete blood count (CBC), liver function tests (aspartate transaminase, alanine transaminase, serum bilirubin, serum albumin, and international normalized ratio), serum creatinine, $\mathrm{HCV}$ antibody, $\mathrm{HBs}-\mathrm{Ag}$, $\alpha$-fetoprotein, and abdominal ultrasound. Liver cirrhosis was confirmed by liver biopsy performed within the last 2 years or by fibroscan and/or Fibrosis-4 (FIB-4) Index for Liver Fibrosis $>3.25$ assessment. Estimation of HCV RNA level was done by Cobas Ampli Prep/Cobas TaqMan HCV-RNA assay (Roche Diagnostics; Pleasanton, CA, USA) with a threshold of detection $15 \mathrm{IU} / \mathrm{mL}$.

\section{Treatment regimens}

Non-cirrhotic naïve patients were treated with sofosbuvir (Soflanork, Mash Company, Cairo, Egypt; 400 mg, orally, once daily) plus daclatasvir (Daklanork, Mash company, Egypt; $60 \mathrm{mg}$, orally, once daily) for 12 weeks. Weight-based ribavirin (Ribovinol, Mash Company; 1200 or 1000 mg/day if $\geq 75$ or $<75 \mathrm{~kg}$ body weight, respectively) was added to this regimen when treating cirrhotic patients and/or treatmentexperienced patients who received prior interferon therapy. Treatment duration was extended to 24 weeks with addition of weight-based ribavirin only in treatment-experienced patients who failed to respond to sofosbuvir plus ribavirin regimen. The effectiveness of sofosbuvir plus daclatasvir with or without ribavirin was measured by the number of patients with successful elimination of the virus, illustrated by sustained virologic response at 12 weeks after the end of treatment (SVR12). SVR12 was defined as undetectable HCV-RNA $(<15 \mathrm{IU} / \mathrm{mL})$ at 12 weeks after the end of treatment. Safety was assessed by the occurrence of adverse effects associated with this therapy.

Follow-up was done by clinical assessment of the patients and reviewing the results of laboratory tests ( $\mathrm{CBC}$, liver function tests, and renal function tests) at weeks 4, 8, and 12 of the treatment. Quantitative real-time PCR for HCV RNA was done at 12 weeks post-treatment to confirm SVR. Primary outcome was the number of patients who achieved SVR12, and secondary outcome was the occurrence of adverse events associated with this therapy.

\section{Statistical analysis}

The statistical significances between studied groups were analyzed using unpaired $t$-test (for quantitative variables), Chi-square test, and Fisher's exact test (for qualitative variables). Statistical tests were performed with SPSS (Version 23). $P$-values $<0.05$ were considered statistically significant.

\section{Results}

Three hundred patients with chronic HCV infection were enrolled in this study. The baseline demographic and laboratory data are shown in Table 1. 
Table I Baseline demographic and laboratory data of the studied patients

\begin{tabular}{llll}
\hline Variables & & Number (300) & $\%$ \\
\hline Age (years) & Mean \pm SD & $49.73 \pm 10.97$ & \\
Sex & Male & 178 & 59.33 \\
& Female & 122 & 40.67 \\
Liver status & Non-cirrhotic & 203 & 67.67 \\
& Cirrhotic & 97 & 32.33 \\
Child-Pugh score & Child A & 77 & 79.38 \\
(N:97) & Child B & 20 & 20.62 \\
History of & Treatment-naire & 238 & 79.33 \\
treatment & Treatment-experienced & 62 & 20.67 \\
History of diabetes & Non-diabetic & 228 & 76 \\
mellitus & Diabetic & 72 & 24 \\
Hb (g/dL) & Mean $\pm S D$ & $13.26 \pm 1.71$ & \\
WBC $\left(\times 10^{3}\right) / \mathrm{mm}^{3}$ & Mean $\pm S D$ & $6.44 \pm 2.15$ & \\
Platelet $\left(\times 10^{3}\right) / \mathrm{mm}^{3}$ & Mean \pm SD & $207.27 \pm 92.88$ & \\
ALT (IU/L) & Mean $\pm S D$ & $57.39 \pm 42.93$ & \\
AST (IU/L) & Mean $\pm S D$ & $57.54 \pm 32.93$ & \\
Serum bilirubin & Mean $\pm S D$ & $1.36 \pm 0.40$ & \\
(mg/dL) & & & \\
Serum albumin & Mean $\pm S D$ & $4.12 \pm 0.54$ & \\
$(\mathrm{mg} / \mathrm{dL})$ & & & \\
INR & Mean $\pm S D$ & $1.51 \pm 0.22$ &
\end{tabular}

Abbreviations: ALT, alanine transaminase; AST, aspartate transaminase; $\mathrm{Hb}$, hemoglobin; INR, international normalized ratio; WBC, white blood cells.

Table 2 Primary outcome of treatment in the studied patients (sustained virologic response at 12 weeks)

\begin{tabular}{llll}
\hline Variables & $\begin{array}{l}\text { Number of } \\
\text { the studied } \\
\text { patients }\end{array}$ & $\begin{array}{l}\text { Sustained } \\
\text { virologic response } \\
\text { at I2 weeks }\end{array}$ \\
\cline { 3 - 4 } & & $\mathbf{N}$ & $\%$ \\
\hline Overall patients & 300 & 278 & 92.67 \\
Non-cirrhotic patients & 203 & 196 & 96.55 \\
Cirrhotic patients & 97 & 82 & 84.54 \\
Treatment-naïe patients & 238 & 224 & 94.12 \\
Treatment-experienced patients & 62 & 54 & 87.0 I \\
\hline
\end{tabular}

The primary outcome of sofosbuvir plus daclatasvir with or without ribavirin at $12-24$ weeks was detected by SVR12 as demonstrated in Table 2.

With regard to the number of patients who presented with side effects: only 59 patients (19.7\%) reported minor adverse events. The adverse events were mainly fatigue in 27 patients (9\%), anemia in 17 patients (5.67\%) (this side effect occurred only in patients who received ribavirin), headache in 12 patients $(4 \%)$, and insomnia in 7 patients $(2.3 \%)$ as shown in Table 3. Dose reduction of ribavirin was done in 17 patients $(5.67 \%)$ patients in whom hemoglobin levels had decreased below $10 \mathrm{~g} / \mathrm{dL}$.

Analyses of what could have affected the response to treatment revealed that older age, liver cirrhosis, especially
Table 3 Incidence of side effects during the treatment period in the studied patients

\begin{tabular}{lll}
\hline Side effects & Number (300) & $\%$ \\
\hline No side effects & 241 & 80.3 \\
Had side effects & 59 & 19.7 \\
Fatigue & 27 & 9.0 \\
Anemia & 17 & 5.67 \\
Headache & 12 & 4.0 \\
Insomnia & 7 & 2.3 \\
Diarrhea & 3 & 1.0 \\
Nausea & 5 & 1.7 \\
Cough & 4 & 1.3 \\
Myalgia & 1 & 0.3 \\
\hline
\end{tabular}

Notes: Some patients had more than one side effect.

Child-Pugh class B, and low platelet count were the factors that were significantly associated with non-response to treatment as shown in Table 4.

\section{Discussion}

In this study, non-cirrhotic naïve patients were treated with sofosbuvir plus daclatasvir for 12 weeks. Ribavirin was added to this regimen when treating cirrhotic patients and/or treatmentexperienced patients. Treatment duration was extended to 24 weeks only in treatment-experienced patients who failed to respond to sofosbuvir plus ribavirin regimen. Two hundred seventy-eight (92.67\%) patients achieved successful eradication of HCV. SVR 12 was $96.55 \%$ and $84.54 \%$ in non-cirrhotic and cirrhotic patients, respectively. SVR12 in treatment-naïve and treatment-experienced patients were $94.12 \%$ and $87.01 \%$, respectively. With regard to the number of patients who presented with side effects: only 59 patients $(19.7 \%)$ reported minor adverse events. The adverse events were mainly fatigue in 27 patients (9\%), anemia in 17 patients $(5.67 \%)$, headache in 12 patients (4\%), and insomnia in 7 patients (2.3\%).

Our results were in accordance with Fontaine et al who concluded that combination of sofosbuvir and daclatasvir was associated with a high rate of SVR in treatment of genotype $4 \mathrm{HCV}^{18}$ Forty-seven patients with genotype $4 \mathrm{HCV}$ were enrolled in their study and received a combination of sofosbuvir and daclatasvir with or without ribavirin for 12 or 24 weeks, respectively. The overall SVR was $86 \%-100 \%$, according to patients' baseline characteristics and therapeutic regimen. They also concluded that there was a beneficial effect in treatment-experienced and cirrhotic patients when either ribavirin was added or treatment duration was extended from 12 to 24 weeks, and the combination of sofosbuvir plus daclatasvir was generally well tolerated with mild adverse events.

In a recent Egyptian study including $>18,000$ patients with HCV infection, about 95\% achieved SVR12. It was 
Table 4 Predictors of non-response to therapy in the studied patients

\begin{tabular}{|c|c|c|c|c|c|c|}
\hline \multirow[t]{2}{*}{ Variables } & & \multicolumn{2}{|c|}{$\begin{array}{l}\text { Responders } \\
(\mathrm{N}=\mathbf{2 7 8 )}\end{array}$} & \multicolumn{2}{|c|}{$\begin{array}{l}\text { Non responders } \\
(\mathrm{N}=22)\end{array}$} & \multirow[t]{2}{*}{$P$-value } \\
\hline & & $\mathbf{N}$ & $\%$ & $\mathbf{N}$ & $\%$ & \\
\hline Age (years) & Mean $\pm S D$ & \multicolumn{2}{|c|}{$49.38 \pm I I .14$} & \multicolumn{2}{|c|}{$53.79 \pm 7.72$} & $0.0 I^{*}$ \\
\hline \multirow[t]{2}{*}{ Sex } & Male & 166 & 59.71 & 12 & 54.54 & 0.63 \\
\hline & Female & 112 & 40.29 & 10 & 45.45 & \\
\hline \multirow[t]{2}{*}{ Liver status } & Non-cirrhotic & 196 & 70.5 & 7 & 31.82 & $0.0002^{*}$ \\
\hline & Cirrhotic & 82 & 29.5 & 15 & 68.18 & \\
\hline \multirow[t]{2}{*}{ Child-Pugh score } & Child A & 71 & 86.59 & 6 & 40 & $<0.000$ I* \\
\hline & Child B & 11 & $13.4 \mid$ & 9 & 60 & \\
\hline \multirow[t]{2}{*}{ History of treatment } & Naïve & 224 & 80.58 & 14 & 63.64 & 0.06 \\
\hline & Experienced & 54 & 19.42 & 8 & 36.36 & \\
\hline \multirow[t]{2}{*}{ History of diabetes mellitus } & Non-diabetic & 214 & $76.98 \%$ & 14 & 63.64 & 0.16 \\
\hline & Diabetic & 64 & $23.02 \%$ & 8 & 36.36 & \\
\hline $\mathrm{Hb}(\mathrm{g} / \mathrm{dL})$ & Mean \pm SD & \multicolumn{2}{|c|}{$13.29 \pm 1.72$} & \multicolumn{2}{|c|}{$12.82 \pm 1.63$} & 0.20 \\
\hline WBC $\left(\times 10^{3}\right) / \mathrm{mm}^{3}$ & Mean \pm SD & \multicolumn{2}{|c|}{$6.49 \pm 2.18$} & \multicolumn{2}{|c|}{$5.84 \pm 1.74$} & 0.13 \\
\hline Platelet $\left(\times 10^{3}\right) / \mathrm{mm}^{3}$ & Mean \pm SD & \multicolumn{2}{|c|}{$210.41 \pm 94.66$} & \multicolumn{2}{|c|}{$171.15 \pm 59.29$} & $0.02^{\mathrm{a}}$ \\
\hline ALT (IU/L) & Mean \pm SD & \multicolumn{2}{|c|}{$58.44 \pm 44.19$} & \multicolumn{2}{|c|}{$45.22 \pm 21.94$} & 0.26 \\
\hline AST (IU/L) & Mean $\pm S D$ & \multicolumn{2}{|c|}{$57.54 \pm 33.18$} & \multicolumn{2}{|c|}{$57.44 \pm 30.58$} & 0.89 \\
\hline HCV viral load & Mean \pm SD & \multicolumn{2}{|c|}{$1019150.9 \pm 3559000.2$} & \multicolumn{2}{|c|}{$1190846.5 \pm 1846267.7$} & 0.15 \\
\hline
\end{tabular}

Notes: aSignificant. *Statistically significant at $P \leq 0.05$.

Abbreviations: ALT, alanine transaminase; AST, aspartate transaminase; HCV, hepatitis C virus; Hb, hemoglobin; WBC, white blood cells.

concluded that this regimen is safe and effective for the treatment of Egyptian patients with chronic hepatitis $\mathrm{C}$ genotype $4 .{ }^{19}$

Buti et al as well stated that most of the approved oral DAA regimens provided high cure rates with very low incidence of adverse events, especially in non-cirrhotic patients. ${ }^{20}$

Our results were in agreement with the study performed by Pol et al who documented that combination of sofosbuvir and daclatasvir had high antiviral potency, with $>90 \%$ SVR rate in patients with chronic $\mathrm{HCV}$ infection. ${ }^{10}$ Moreover, SVR rate improved in treatment-experienced and cirrhotic patients when ribavirin was added for 12 weeks. In addition, treatment with sofosbuvir and daclatasvir was well tolerated, had limited adverse events, as well as a good safety profile.

With regard to the predictive factors associated with non-response to therapy, various host and viral variables (e.g., gender, age, race, body mass index, insulin resistance, steatosis, advanced fibrosis stage, HCV genotype, and viral load) had been well identified and were associated with nonresponse to interferon based therapies. ${ }^{21-23}$ Currently, with the more recent generations of pan-genotypic oral DAA, there are higher rates of SVR, and hence, the aforementioned predictive factors might not have the same importance and strength as they did before. ${ }^{24}$

Our results revealed that older age, cirrhosis, especially Child-Pugh class B, and low platelet count were the predictors of non-response associated with sofosbuvir and daclatasvir therapy for genotype $4 \mathrm{HCV}$ among Egyptian patients.
This might be attributed to the fact that most of the patients with older age and/or low platelet count in our study were associated with liver cirrhosis at presentation likely caused by a longer duration of HCV infection.

With regard to age, few studies showed the relation of older age to SVR rates using all oral DAA regimens because elderly patients were often excluded from clinical trials. However, little differences in SVR rates were observed between elderly patients and younger ones. ${ }^{25,26}$

With regard to liver status, Ferenci et al reported that the severity of hepatic dysfunction appeared to affect the response rate to DAA, with higher SVR in patients with chronic hepatitis or Child A liver cirrhosis than in those with Child B or C liver cirrhosis. ${ }^{27}$

Buti et al reported that the number of patients with treatment failure was relatively low as SVR rates were generally high with most different DAA regimens. ${ }^{20}$ Reduced response rates occurred more frequently in treatment-experienced patients, those with advanced cirrhosis, HCV genotypes 3 or 1a infections, elevated serum HCV-RNA, poor drug adherence or premature drug discontinuation.

The limitation of this work was that Child $\mathrm{C}$ patients were excluded, who might be less likely to have a response and also at higher risk of side effects.

\section{Conclusion}

Based on this multi-center prospective study, combined sofosbuvir plus daclatasvir with or without ribavirin for 
12-24 weeks appears to have favorable outcomes with high rates of SVR and safety profile in the treatment of Egyptian patients with genotype $4 \mathrm{HCV}$ infection. Older age, cirrhosis, especially Child-Pugh class B, and low platelet count are independent risk factors of treatment non-response. Sofosbuvir plus daclatasvir regimen should be considered in the treatment of genotype $4 \mathrm{HCV}$-infected patients. Large-scale studies of sofosbuvir plus daclatasvir for the treatment of chronic HCV, particularly in the so-called "difficult-to-treat" patients, are recommended.

\section{Disclosure}

The authors report no conflicts of interest in this work.

\section{References}

1. Mohd Hanafiah K, Groeger J, Flaxman AD, Wiersma ST. Global epidemiology of hepatitis $\mathrm{C}$ virus infection: new estimates of age specific antibody to HCV seroprevalence. Hepatology. 2013;57:1333-1342.

2. Guerra J, Garenne M, Mohamed MK, Fontanet A. HCV burden of infection in Egypt: results from a nationwide survey. J Viral Hepat. 2012;19:560-567.

3. Wantuck JM, Ahmed A, Nguyen MH. Review article: the epidemiology and therapy of chronic hepatitis $\mathrm{C}$ genotypes 4,5 and 6. Aliment Pharmacol Ther. 2014;39:137-147.

4. Elwan N, Elfert A, Abd-Elsalam S, et al. Study of hepatic steatosis index in patients with chronic HCV infection. Int J Curr Microbiol App Sci. 2016;5(5):266-274.

5. Ahmed OA, Kaisar HH, Hawash N, et al. Efficacy of sofosbuvir plus ribavirin with or without peginterferon-alfa in treatment of a cohort of Egyptian patients with hepatitis C virus infection. Infect Disord Drug Targets. 2017;17(2):95-100.

6. Abd-Elsalam S, Sharaf-Eldin M, Soliman S, Elfert A, Badawi R, Ahmad YK. Efficacy and safety of sofosbuvir plus ribavirin for treatment of cirrhotic patients with genotype 4 hepatitis $C$ virus in real-life clinical practice. Arch Virol. Epub 2017;163:51-56.

7. Hajarizadeh B, Grebely J, Dore GJ. Epidemiology and natural history of HCV infection. Nat Rev Gastroenterol Hepatol. 2013;10: 553-562.

8. Backus LI, Boothroyd DB, Phillips BR, Belperio P, Halloran J, Mole LA. A sustained virologic response reduces risk of all-cause mortality in patients with hepatitis C. Clin Gastroenterol Hepatol. 2011;9: 509-516.

9. Morgan RL, Baack B, Smith BD, Yartel A, Pitasi M, Falck-Ytter Y. Eradication of hepatitis $\mathrm{C}$ virus infection and the development of hepatocellular carcinoma: a meta analysis of observational studies. Ann Intern Med. 2013;158:329-337.
10. Pol S, Corouge M, vallet-Pichard A. Daclatasvir-sofosbuvir combination therapy with or without ribavirin for hepatitis $\mathrm{C}$ virus infection: from the clinical trials to real life. Hepat Med. 2016;8:21-26.

11. Bunchorntavakul C, Reddy KR. Review article: the efficacy and safety of daclatasvir in the treatment of chronic hepatitis $\mathrm{C}$ virus infection. Aliment Pharmacol Ther. 2015;42:258-272.

12. Sulkowski MS, Gardiner DF, Rodriguez-Torres M, Reddy KR, Hassanein T, Jacobson I. Daclatasvir plus sofosbuvir for previously treated or untreated chronic hCV infection. N Engl J Med. 2014;370:211-221.

13. Kohli A, Kapoor R, Sims Z, et al. Ledipasvir and sofosbuvir for hepatitis C genotype 4: a proof-of-concept, single-centre, open-label phase 2a cohort study. Lancet Infect Dis. 2015;15:1049-1054.

14. Abergel A, Loustaud-Ratti V, Metivier S, et al. Ledipasvir/sofosbuvir treatment results in high SVR rates in patients with chronic genotype 4 and 5 hov infection. J Hepatol. 2015;62 219-220.

15. El Raziky M, Gamil M, Hammad R, et al. Treatment of hepatitis C genotype 4 patients with simeprevir and sofosbuvir: preliminary results from a phase IIa, partially randomised, open-label trial conducted in Egypt (OSIRIS). Hepatology. 2015;62:145.

16. Asselah T, Hassanein TI, Qaqish RB, et al. Efficacy and safety of ombitasvir/paritaprevir/ritonavir co-administered with ribavirin in adults with genotype 4 chronic hepatitis $\mathrm{C}$ infection and cirrhosis (Agate-I). Hepatology. 2015;62:119.

17. Asselah T. Daclatasvir plus sofosbuvir for $\mathrm{HCV}$ infection: an oral combination therapy with high antiviral efficacy. J Hepatol. 2014;61:435-438.

18. Fontaine H, Hezode C, Zoulim F, et al. Efficacy of the oral sofosbuvir based combinations in HCV genotype 4-monoinfected patients from the French observational cohort ANRS CO22 Hepather. Abstract LP28 presented at: 50th Annual Meeting of European Association for the Study of the Liver; April 22-26, 2015; Vienna, Austria.

19. Omar H, El Akel W, Elbaz T, et al. Generic daclatasvir plus sofosbuvir, with or without ribavirin, in treatment of chronic hepatitis C: realworld results from 18378 patients in Egypt. Aliment Pharmacol Ther. 2018;47(3):421-431.

20. Buti M, Riveiro-Barciela M, Esteban R. Management of direct antiviral agent failures. J Hepatol. 2015;63:1511-1522.

21. Afdhal NH, McHutchison JG, Zeuzem S, et al. Hepatitis C pharmacogenetics: state of the art in 2010. Hepatology. 2011;53:336-345.

22. Hadziyannis SJ, Sette H, Morgan TR, et al. Peginterferon alpha 2a and ribavirin combination therapy in chronic hepatitis $\mathrm{C}$ : a randomized study of treatment duration and ribavirin dose. Ann Intern Med. 2004;140:346-355.

23. Manns MP, Wedemeyer H, Cornberg M. Treating viral hepatitis C: efficacy, side effects, and complications. Gut. 2006;55:1350-1359.

24. Cavalcante LN, Lyra AC. Predictive factors associated with hepatitis $\mathrm{C}$ antiviral therapy response. World J Hepatol. 2015;7(12):1617-1631.

25. Reid M, Price JC, Tien PC. Hepatitis C virus infection in the older patient. Infect Dis Clin NAm. 2017;31:827-838.

26. Saab S, Park SH, Mizokami M, et al. Safety and efficacy of ledipasvir/ sofosbuvir for the treatment of genotype 1 hepatitis $\mathrm{C}$ in subjects aged 65 year or older. Hepatology. 2016;63(4):1112-1119.

27. Ferenci P, Kozbial K, Mandorfer M, Hofer H. HCV targeting of patients with cirrhosis. J Hepatol. 2015;63:1015-1022.
Infection and Drug Resistance

\section{Publish your work in this journal}

Infection and Drug Resistance is an international, peer-reviewed openaccess journal that focuses on the optimal treatment of infection (bacterial, fungal and viral) and the development and institution of preventive strategies to minimize the development and spread of resistance. The journal is specifically concerned with the epidemiology of antibiotic

\section{Dovepress}

resistance and the mechanisms of resistance development and diffusion in both hospitals and the community. The manuscript management system is completely online and includes a very quick and fair peerreview system, which is all easy to use. Visit http://www.dovepress.com/ testimonials.php to read real quotes from published authors. 